\title{
FIGURACIONES POSNACIONALES Y POSGLOBALES EN CAMINANDO BAJO EL MAR, COLGANDO DEL AMPLIO CIELO (2017) DE PATRICIO PRON ${ }^{1}$
}

\author{
POSTNATIONAL AND POSTGLOBAL REPRESENTATIONS IN CAMINANDO \\ BAJO EL MAR, COLGANDO DEL AMPLIO CIELO (2017) BY PATRICIO PRON
}

\author{
María Belén Bernardi \\ Instituto de Estudios Críticos en Humanidades \\ (Universidad Nacional de Rosario-CONICET) \\ Argentina \\ mariabelenbernardi@gmail.com
}

\begin{abstract}
Resumen: En este artículo abordaremos las representaciones de grupos sociales y sujetos migrantes desde el desmantelamiento de las nociones de nacionalismo y cosmopolitismo en el libro infantil de Patricio Pron, Caminando bajo el mar, colgando del amplio cielo (2017). Por una parte, analizaremos de qué manera se construye la condición subjetiva y mundial del refugiado, cuya imagen es introducida por el propio autor en distintas declaraciones. Por otra parte, indagaremos acerca de los modos de emergencia de lo autobiográfico en el relato y la construcción de una figura de escritor diaspórico, carente de hogar, a partir de las posibles incidencias de la elección del género fábula, ya que creemos que el autor deposita en el público infantil las posibilidades de concreción de un futuro utópico, garante de hospitalidad universal, asimilable a aquel que pregonara Kant en "Sobre la paz perpetua".
\end{abstract}

Palabras clave: Cosmopolitismo - fábula - literatura infantil - migración - posnacionalismo.

Abstract: In this paper, we will examine the representations of social groups and
migrant subjects from the dismantling of the notions of nationalism and cosmopoli-
tanism in Patricio Pron's latest children's book, Caminando bajo el mar, colgando del
amplio cielo (2017). On the one hand, we will analyze how the subjective and global
condition of the refugee is built. This image is introduced by the author himself in

${ }^{1}$ Una versión preliminar de este artículo fue presentada en "La ciudad que yo inventé", Primeras Jornadas de Literatura de Rosario del Centro de Estudios de Literatura Argentina (Universidad Nacional de Rosario), llevadas a cabo en junio de 2018. 
different places. On the other hand, we will investigate about the autobiographical aspects of the story and the construction of the figure of the diasporic writer. Also we will ask about the choice of the fable genre, since we believe that the author places in the children's audience the possibilities of realization of a utopian future, guarantor of universal hospitality, similar to that proclaimed by Kant in "Perpetual Peace".

Keywords: Cosmopolitanism - fable - children's literature - migration - postnationalism.

Recibido: 11/03/2020. Aceptado: 16/11/2020.

...a partir de un momento, que no es cuestión de fechar con precisión pero que se podría situar justo después del Guernica, todo este conjunto de esquematismos posibles (del arte) desapareció, hasta el esquematismo del hombre mismo, las diferentes figuras del hombre y la humanidad. Esta desaparición de los esquemas, de las figuras, como soportes de las posibilidades para crear formas, esta desaparición es aquella que caracteriza al mundo actual, que hace que estemos en un mundo que se encuentra de algún modo en pérdida de mundo, en pérdida de sentido, en la ausencia de grandes esquemas, de grandes ideas reguladoras, ya sean religiosas, políticas y en consecuencia también estéticas (Jean-Luc Nancy, El arte hoy).

$\mathrm{E}$ n el presente trabajo nos proponemos analizar las representaciones de grupos sociales y sujetos migrantes desde el desmantelamiento de las nociones de nacionalismo y cosmopolitismo en el último libro infantil de Patricio Pron. Por una parte, indagaremos acerca de los modos de emergencia de lo autobiográfico en el relato, teniendo en consideración que el autor ha sido, como el protagonista de dicho libro, un argentino que desea cruzar el océano en busca de mejores condiciones de vida. Por otra parte, repararemos en la manera en que se construye la condición subjetiva y mundial del refugiado, cuya figura es introducida por el propio autor en la construcción del relato acerca de la génesis de este libro, con motivo de la actual crisis de refugiados en Europa. Por último, analizaremos la construcción de una figura de escritor diaspórico, carente de hogar, a partir de las posibles incidencias de la elección del género fábula, en tanto consideramos que el autor deposita en el público infantil las posibilidades de concreción de un 
futuro utópico, garante de justicia y de hospitalidad universal.

Caminando bajo el mar, colgando del amplio cielo (2017a) relata la historia de Nahuel, un venado argentino que ante la sequía que asedia las pampas, causada por el hombre, emprende una travesía hasta Europa con un grupo de amigos, en busca de mejores condiciones de vida. A raíz de su publicación, Patricio Pron dedica una carta a Edward Lear, de cuyos limericks se manifiesta deudor, en la que explicita el tema de este libro, perteneciente a la "mal llamada literatura infantil":

Últimamente me acuerdo mucho de usted porque acaban de publicar una pequeña novela mía: sorprendentemente, dicen que es "para niños". Pero ¿qué determina que un libro lo sea? (...) Mi pequeña novela trata un tema que no parece "infantil": la responsabilidad que nos cabe (y preferimos ignorar) frente a las personas que se ven forzadas a marcharse de su país de origen; lo hace con un venado, un puercoespín, un cerdo que finge ser un perro, una ballena suspendida en el aire sobre Europa. Y sin embargo, posiblemente sea el libro más personal y autobiográfico que haya escrito en mi vida (Pron, 2017b).

La aparente contradicción se disuelve ante la voluntad del autor de que en esta obra se reúnan varias generaciones de lectores, lo cual coincide con la descripción de la colección "Las tres edades", destinada a un público de entre 8 a 88 años, de la editorial Siruela, en la que fue publicada.

La veta autobiográfica se pone de manifiesto desde el inicio, en primer lugar, debido a que se trata de personajes migrantes o "seres en tránsito" (2017c), cuya experiencia es asimilable al itinerario del propio autor, nacido en Rosario, doctorado en Alemania y residente en Madrid desde 2008. Esta identificación se evidencia además en la rememoración de la génesis del relato, que sucede a partir de la visita a una reserva natural en la provincia de Santa Fe. Relata Pron:

Supongo que después de visitarla me quedé pensando en la situación de esos animales (expulsados de su sitio por el hombre) y en el trabajo de quienes procuran darles un refugio. Y es posible que también haya pensado en mí, que en ese momento estaba a punto de marcharme a Alemania. Quizás pensé que uno de esos temas iluminaba el otro y escribí el texto, a la espera de que le llegara su momento. Y ese momento llegó este año, cuando las sucesivas «crisis de los refugiados» (que, con- 
tra lo que la prensa afirma habitualmente no suceden «a las puertas de Europa» sino «en Europa» y hacen a las dificultades de concebir el suyo como un proyecto verdaderamente democrático y plural) me hicieron volver a pensar en él (Sainz Borgo, 2018).

Caminando bajo el mar... se construye entonces a partir de una serie de tópicos mutuamente imbricados: por un lado, la impugnación de cualquier criterio nacionalista y esencialista de definición de una identidad, una patria y una tradición literaria. Por otro, el fracaso del proyecto de entidades supranacionales como la Unión Europea que se evidencia a partir de la crisis de los refugiados, cuya figura se hace extensiva a la del propio autor, y con él a diversos sujetos migrantes, exiliados, errantes, cuyos derechos son vulnerados y su posibilidad de supervivencia cercenada. Como contrapartida, aparece la mención de refugio en su sentido primigenio de protección así como también el recordatorio urgente de la responsabilidad que le cabe a la ciudadanía mundial de brindar resguardo ante el desamparo de grupos sociales enteros que se encuentran en dicha situación de emergencia.

La pérdida de los grandes esquemas reguladores que menciona Nancy en nuestro epígrafe se puede vincular con la caducidad de los términos "nación", "identidad" y "cosmopolitismo" que operan en la actualidad. De acuerdo con las teorizaciones posnacionales de Castany (2007) que recoge Mandolessi (2011), "la erosión del estado nación o del nacionalismo supone la crisis de todo el sistema moderno: una crisis del concepto de ciudadanía, una crisis cultural e identitaria y en un sentido amplio, una crisis epistémica, crisis que permiten asociar la posnacionalidad estrechamente con la posmodernidad" (p. 64). En este sentido, es posible tomar lo que la autora relata acerca de Félix en Los incompletos, de Sergio Chejfec, como una definición del desmantelamiento del cosmopolitismo en tanto visión optimista de lo que significaría una ciudadanía global que dote al sujeto de sentido de pertenencia y que garantice sus derechos fundamentales: "en lugar de ser un 'ciudadano del mundo' que se siente en casa en todas partes, aquí la sensación es inversa: la de no estar en casa en ningún lugar” (Mandolessi, 2011, p. 75). Algo similar a lo que el propio Pron manifiesta acerca de no haberse sentido "en casa" en ninguno de los sitios en los cuales vivió (Friera, 2009).

Esto se contrapone con la visión eufórica, propia de la modernidad, de 
un "mundo producido como totalidad cultural" a partir de la globalización (Siskind, 2016, p. 57), que devendría a su vez en una promesa, finalmente fallida, de emancipación. De acuerdo con Nancy (2003), el globo, corroído, no es más que una aglomeración en la que

se pone en juego la conjunción de un crecimiento indefinido de la tecnociencia, de un crecimiento correlativo exponencial de la población, de un agravamiento en ella de las desigualdades de todos los órdenes -económico, biológico, cultural- y de una disipación desorientada de las certidumbres, imágenes e identidades de aquello que fue el mundo con sus partes y la humanidad con sus caracteres (p. 14).

Respecto de la identidad, Pron plantea que esta "no es un punto de partida sino de llegada”. Dicha frase se encuentra presente en múltiples entrevistas y artículos del autor y, en el caso del presente libro, es encarnada por un cerdo que se cree perro y luego, ya en la celda donde han encerrado a todos los animales que desde distintos lugares del mundo lograron llegar a la anhelada Europa, por una jirafa que finge ser perro como medida de protección. Que la identidad es un proceso de construcción que parte desde el propio sujeto y no desde categorías externas, ajenas a él, se manifiesta ante la negativa de ciertos animales de ver (o aceptar) el modo en que la jirafa y el cerdo se presentan ante el mundo, recordándoles que no son lo que dicen ser. Esto enlaza de manera directa con la problemática que el autor plantea en torno a la identidad definida a partir de un origen geográfico y al desafío que supone pensar, como le gusta expresarlo, que no son las personas quienes pertenecen a los lugares sino los lugares los que pertenecen a las personas. Consecuentemente, la idea de nación (y el nacionalismo que en ocasiones conlleva) resulta cuestionada:

Quienes hemos tenido la oportunidad de vivir en varios países y que hemos visto una y otra vez cómo el nacionalismo era exacerbado para articular en torno a él los proyectos políticos más totalitarios y empobrecedores de los últimos años, tendemos a reconocer la otredad como la única identidad a la que podemos abrazarnos. Las identidades que se proyectan sobre mi figura, por ejemplo, como la del escritor argentino que vive en España, que publica en varios países, que vivió en Alemania... nunca son determinadas por mí. Me dan absolutamente igual (Megías, 2017). 
Resulta interesante remarcar el hecho de que reflexionar sobre la identidad desde una lógica de abordaje que prescinde de la nación como categoría privilegiada implica además revisar los modelos de configuración y adscripción a una tradición literaria nacional, así como también los paradigmas académicos, teóricos y críticos basados en dicho criterio. En este último aspecto se basa el trabajo de Marcelo Topuzian, que destaca cómo en las últimas décadas la antropología, la sociología la filosofía y la teoría política "han puesto fecha de caducidad, más o menos cercana según los casos, al estado-nación, para iluminar los aspectos globales, mundiales o transnacionales de la cultura contemporánea" (2014, p. 96). Y resalta además los peligros de la presentación del Estado como realización pura de la inmanencia de una comunidad nacional totalitaria. Según su perspectiva,

la abyección de lo que es necesario separar para garantizar dicha pureza, fuente y a la vez resultado del carácter constitutivamente racista de los nacionalismos contemporáneos, ya sea bajo la figura del extranjero, del cosmopolita, del diaspórico, del migrante o, simplemente, del indigente, revela el carácter de sutura imaginaria del nacionalismo respecto de lo real del carácter en última instancia infundado de cualquier sistema político, de cualquier Estado (Topuzian, 2017, p. 16).

De manera particular, en Caminando bajo el mar..., Pron pone en acto el castigo, la violencia y la burocracia que pesa sobre los extranjeros a los que se solicita un cúmulo absurdo de papeles para poder quedarse en Europa, similar al documento de identidad nacional que los "burócratas culturales" solicitan a los escritores (Lamberti, 2017) para poder encasillarlos y de ese modo, comprenderlos.

En este sentido, el maltrato que reciben los extranjeros da cuenta de una imposibilidad del "bien-vivir-juntos", que postula Nancy (2003, p. 15) así como también de una concepción completamente negativa de un mundo que expulsa a sus integrantes en un doble movimiento: desde el país de origen y en el país receptor. Caminando bajo el mar...pareciera entonces poner en acto la idea de Nancy (2003) de que

el mundo ha perdido su capacidad de hacer mundo. Parece haber ganado solamente la de multiplicar a la medida de sus medios una proliferación de lo inmundo que, hasta aquí, a pesar de lo que se pueda pensar acerca de las ilusiones retrospectivas, nunca antes en la historia había 
marcado de esta manera la totalidad del orbe. En definitiva, todo sucede como si el mundo estuviera trabajado y atravesado por una pulsión de muerte que pronto no tendría ninguna otra cosa que destruir sino al propio mundo (p. 16).

El libro también pone en escena la falta de empatía y la incomprensión que se manifiesta hacia los personajes que solicitan refugio y asilo, lo cual se opone a la globalización "entendida como una oportunidad para que toda la Tierra sea un espacio unificado de comunicación que ha de unir a toda la humanidad" (Žižek, 2016, p. 85). Como se plantea en el relato, los animales hablan distintos idiomas, por lo cual no los entienden, pero además nadie se compadece de lo que han sufrido antes, durante y luego de llegar a Europa:

Cualquiera que los hubiese escuchado habría, por fuerza, sentido pena por ellos, porque no habían dejado sus casas por voluntad propia sino desalojados por la guerra, el hambre, la sed, los cazadores y otras calamidades. Sin embargo, cuando por fin se creían a salvo, todos ellos habían sido maltratados y se los había encerrado como si fueran ladrones solo porque buscaban una vida mejor (Pron, 2017a, p. 95).

En este pasaje encontramos una actualización de la definición de "prójimo" como alguien traumático "cuyo modo de vida distinto (...) nos molesta, desestabiliza nuestro modo de vida (...) provocando una reacción agresiva dirigida a librarnos de ese molesto intruso” (Žižek, 2016, p. 86).

Sin embargo, a lo largo de la obra este pesimismo generalizado deviene en una subversión de la idea de extranjería que la dota de un valor positivo, y que convierte en ganancia lo que podría considerarse una pérdida en relación con el abandono de un territorio. Hacia el final de Caminando bajo el mar..., leemos:

En cierta forma, el viaje que Nahuel y sus amigos hicieron es el mismo que miles de personas realizan día tras días, hora tras hora, empujadas por las guerras, el hambre o solo por el deseo de vivir en un sitio mejor. No veas por dónde, pero yo creo que ese viaje enriquece a todos, a los que se marchan y a los que se quedan, y a los que reciben a los que se marchan y les dan un nuevo hogar, y que el beneficio para todos es tan grande que haría falta un escritor mejor que yo para describirlo acertadamente (Pron, 2017a, p. 117) 
Lo mismo cabe decir respecto de la crisis de los refugiados, en tanto, según Pron, conviene recordar que dar refugio implica también un aspecto favorable para la sociedad receptora, que se enriquece al alojar otras tradiciones distintas a la propia (Megías, 2017).

En un sentido análogo, esta ganancia se evidencia en la condición migrante adoptada por Pron de manera consciente como lugar y perspectiva de escritura, construyendo en torno a ella una autopoética (Casas, 2000) que hace del nomadismo y la extranjería su marca distintiva, alimentada a su vez por una genealogía de escritores que han realizado aportes en esa misma dirección (Borges, Copi, Wilcock, Molloy, Fresán, Chejfec, entre otros) y sin los cuales la literatura argentina sería, según Pron, "más pobre" o "bastante menos rica" (Tentoni, 2015). La orilla y la extranjería se constituyen para el autor como una posición enunciativa que provee una perspectiva privilegiada para evaluar la tradición literaria, al tiempo que permite enriquecerla (Iglesia, 2015). Es decir, "escribir desde afuera de todo hogar o espacio nacional” (Iglesia, 2015) es para Pron una decisión estética y a la vez política que hace de la pérdida un beneficio.

Respecto de esta idea de hogar, el autor plantea que "la migración es un lugar sin regreso porque nunca hay un hogar al que regresar. El hogar de quienes nos hemos marchado es el resultado de una serie de prácticas y de lugares en los que hemos vivido, pero no existe un hogar de origen, que es más bien un mito" (Iglesia, 2017). Sin embargo, resulta curioso cómo los lugares, asociados a las prácticas de escritura, adquieren en los dichos de Pron una cierta condición de habitabilidad (asociables a la acción de habitar ligada a la lengua como casa del ser, que postulara Heidegger), en tanto procura aclarar que Caminando bajo el mar... no es el primero en su especie. Rescata entonces el origen de la incursión en los textos infantiles situándolos en un escenario argentino, específicamente el de los Libros del Quirquincho, en los que publica sus primeras contribuciones al género. En este sentido, otra modalidad posible de existencia de algo parecido a un hogar lo constituye el reverso complementario de la escritura, es decir, la instancia de recepción. Dice Pron:

Jamás he tenido la aspiración de ser funcionario de cultura, y por tanto no me he sentido obligado a reivindicar la nacionalidad de una literatura que, en realidad para mí, se inscribe en la corriente subterránea de la literatura argentina producida fuera, pero que al mismo tiempo participa 
de la discusión en Argentina al mismo tiempo que lo hace en España o fuera de ella. En última instancia y más allá de lo que yo piense, mis textos son de quienes los leen y de allí donde los lean (Sainz Borgo, 2018).

A esta misma idea de que los textos pertenecen a los lugares donde son leídos responde el proyecto Trayéndolo todo de regreso a casa (2011), donde se recopilan relatos publicados en el período 1990-2010, en distintos medios locales y editoriales tanto madrileñas como rosarinas y bonaerenses que, en algunos casos no habían sido recogidos en libro. La "casa" a la que se alude responde en este sentido a una comunidad de lectores, es decir, a una instancia de llegada más que de partida, al igual que como ocurría respecto de la identidad. Por otra parte, esa casa exacerba aún más la voluntad de alejamiento de cualquier criterio nacional, en tanto la literatura se constituye para Pron como una "república imaginaria":

En el momento en que un puñado de lectores lee un libro, participa, al menos idealmente, de una comunidad de la que forma parte el autor. Es una comunidad de las más interesantes: no está fijada en ningún territorio, se forma una especie de república imaginaria en la que estamos teniendo conversaciones los lectores y yo acerca de determinados temas (Murcia, 2018).

En este punto, creemos pertinente repasar ciertos postulados esbozados hasta aquí en torno a la "corriente subterránea de la literatura argentina producida afuera", a la pertenencia o no a determinadas tradiciones literarias, a la construcción de modalidades de escritura autopoética signadas por una condición migrante, a la adopción de perspectivas distanciadas como lugar privilegiado desde el cual escribir y, especialmente, a esta última concepción de literatura como "república imaginaria”, para enlazarlos con las reflexiones de otros dos escritores diaspóricos: Sylvia Molloy y Mariano Siskind, cuyas palabras pertenecientes al prólogo de Poéticas de la distancia: adentro y afuera de la literatura argentina (2006), resultan iluminadoras de estas temáticas. Con respecto al punto de partida del libro, centrado en el encuentro de escritores que viven fuera del país, los autores hablan de

la aspiración de reforzar el extrañamiento estético que otorga la dis- 
tancia, al tiempo que intentamos inscribir nuestra escritura y nuestra reflexión en el cuerpo deforme e imaginario de una literatura argentina de la que nos sentimos parte, aun sin poder descifrar sus contornos. ¿De qué maneras participa en esa literatura nacional el escritor desplazado, con su estética migrante? Y más específicamente, ¿̇en qué medida las experiencias concretas de diásporas (...) determinan inscripciones, autoexclusiones y estancias liminares respecto de esa formación nacional vaga e inaprensible que Alberdi llamó (hablando de los resultados de la emigración) “ese país argentino flotante”? Variaciones, en fin, de la pregunta por la existencia de una literatura nacional que se sabe imaginaria pero cuya institucionalidad tiene un peso apreciable en la subjetividad de los escritores que aspiran a formar parte de esa construcción fantasmática (p. 9).

La tensión entre lo "flotante" y el "peso" de la institucionalidad se ponen de manifiesto en un artículo de Pron, que conserva con variantes el mismo nombre del libro, "Trayéndolo todo de regreso a casa. Saer, Copi, Bolaño y la literatura nacional sin nación", donde el escritor cuestiona la representación de Bianciotti (recogida en la Breve historia de la literatura argentina de Martín Prieto) “'como un escritor francés exótico’ más que como uno argentino". A raíz de ello se pregunta:

¿Cómo se construiría la figura del "escritor argentino" y en qué se diferenciaría del "escritor francés exótico"? ¿Qué exotismos no toleraría la literatura argentina, posiblemente la más exótica del subcontinente sudamericano? (...) la reducción de la literatura a la producción nacional ya no es operativa, ya no significa nada ni produce sentido, si es que alguna vez lo produjo. Traer la literatura de regreso a casa es un sinsentido, ya que en realidad esa casa no ha existido nunca, excepto como justificación de un dolor insoportable y un puñado de chistes no muy graciosos" (Pron, 2017c, p. 129).

En este sentido, podría relacionarse la expulsión de ciertos autores del conjunto que se correspondería a la "literatura argentina" con aquella que sufren los animales de la fábula.

Además del impacto sobre la subjetividad, de la que hablaban Molloy y Siskind, que la nación ya no produce sentido y que se trata de un constructo imaginario es, precisamente uno de los contenidos que constituyen el objeto de reflexión de Caminando bajo el mar... Es decir, la concepción de 
nación como ficción, como invención, como fábula, que pone en el centro la construcción de sí a partir de un relato que es, precisamente, la manera en que se autodefinen y presentan los personajes y el modo privilegiado en que ingresan en él las distintas geografías que lo pueblan. Y en este punto, el del relato, ingresa otra veta autobiográfica: Nahuel, el venado argentino, termina "ganándose la vida contando a la gente historias como esta, la de su viaje" (Pron, 2017a, p. 115).

Aquí volvemos a la constatación del inicio, en palabras de Pron, de que este es el libro más autobiográfico y serio que haya escrito y surge, indefectiblemente, la pregunta acerca de qué habría, de manera específica, en la "literatura infantil", que le permite desarrollar sin rodeos y de manera más explícita que en sus libros anteriores la historia de una migración, ya sea forzada o voluntaria, que es la suya propia y la de otros tantos, como sostiene el narrador de la fábula, que se marchan de su país en busca de mejores condiciones de vida.

Una respuesta podría ser la que da el propio autor en una entrevista, en donde afirma que "en el marco de la fábula puedes decir absolutamente todo" (Pron, 2017b), esto es, nuevamente la posición enunciativa de libertad que provee la autofiguración de escritor extranjero, nómada, como veíamos anteriormente. Por otra parte, respecto del final feliz, puesto que finalmente los personajes cumplen su deseo de quedarse a vivir en Europa, el autor aclara que "si el libro termina con una nota esperanzadora no es tanto por la naturaleza del género, sino por la de sus lectores, que tienen toda una vida por delante para constituirse como sujetos políticos" (Megías, 2017).

En este sentido, si bien no existe una moraleja desde la perspectiva tradicional de las convenciones del género, y si bien el autor aclara que no pretende impartir enseñanzas de manera paternalista, lo cierto es que se pone de manifiesto una voluntad concreta de transmitir determinados valores, que se cuelan en la contratapa del libro como una posible -cuestionable o no- “intrusión” didáctica (Díaz Rönner, 1988, p. 16): "un relato conmovedor que explica a los más pequeños por qué las personas abandonan sus hogares en busca de un futuro mejor".

Y si hacemos caso a lo que plantea Graciela Montes (1990) respecto de que "todo lo que los grandes hacemos en torno a la literatura infantil (...) tiene que ver no tanto con los chicos como con la idea que nosotros -los 
grandes- tenemos de los chicos, con nuestra imagen ideal de infancia” (12), entonces cabría suponer que en el ideal de Pron los niños están preparados (quizás mejor que los adultos) para ver en territorio pampeano vacas holandesas, lechuzas que hablan en alemán, topos descendientes de irlandeses, además de abejas sindicalizadas, y en territorio europeo, guanacos bolivianos y monos colombianos, de manera armónica. Como plantea Pron, se trata de que esos

lectores en los que justa o injustamente depositamos el peso del futuro son aquellos que posiblemente encuentren nuevas respuestas a viejas preguntas, y la pregunta de cómo convivir con el otro es una pregunta muy antigua. Quería yo contribuir a este debate apelando a que si hay alguien que posiblemente pueda ofrecer buenas respuestas a preguntas que nos conciernen respecto a qué hacer con los otros (...) son los niños (Omeñaca, 2018).

Una manera, en suma, de contrarrestar la violencia y la hostilidad que recibieron los personajes migrantes de la fábula al llegar a Europa y que podría resumirse, salvando las distancias, en "el derecho cosmopolita" basado en la "hospitalidad universal" que propugnara Kant en el "Tercer artículo definitivo para la paz perpetua". En dicho escrito aclara que no se trata de "filantropía, sino de derecho, y ahí la hospitalidad (Wirtbarkeit) significa el derecho de un extranjero de no ser tratado con enemistad a su llegada a territorio foráneo" (1998, p. 27). Se trataría, entonces, de restituir la posibilidad de una "justicia infinita", en palabras de Nancy (2003), "que debe rendirse a la vez a la propiedad de cada uno y a la impropiedad común de todos" (148), es decir, "el viejo ideal cosmopolita (...) cuyo compromiso abarca toda la comunidad de los seres humanos" (Nussbaum, 1999, p. 14).

A modo de conclusión, lo que se halla presente en este libro de Pron es, en primer lugar, y tomando prestadas nuevamente palabras de Molloy y Siskind (2006), una sutil autobiografía diferida, desplazada, que reconstruye "la figura de escritor que la engendra" y que pone en escena "las condiciones de posibilidad concretas de esa escritura extrañada que es la casa del escritor diaspórico" (p. 12). En segundo lugar, la advertencia de que esa casa, según el recorrido hasta aquí transitado, no existe y si existe es una ficción. Por último, un posicionamiento bivalente respecto de la idea de nación y de mundo, por un lado, desde una perspectiva pesimista debido 
a las múltiples exclusiones de las que son víctimas los sujetos migrantes, exiliados y refugiados, pero por otro el horizonte del cumplimiento de una demanda ética y política de justicia, de una utopía de futuro inclusivo que encuentra en el público infantil, destinatario de la fábula, su promesa de realización.

\section{Bibliografía}

Díaz Rönner, M. A. (1988). Cara y cruz de la literatura infantil. Buenos Aires: Libros del Quirquincho.

Friera, S. (2009, 15 de junio). "El Estado es un gran constructor de ficciones”. Recuperado de: https://www.pagina12.com.ar/diario/suplementos/espectaculos/4-14223-2009-06-15.html.

Iglesia, A. M. (2015, 13 de febrero). "Actuar en el lenguaje es hacerlo en la realidad”. Recuperado de: http://revistadeletras.net/pron-actuar-enel-lenguaje-es-hacerlo-en-la-realidad.

. (2017, 27 de noviembre). "Hay que comprender los enormes beneficios que implica la aceptación de la diferencia y del otro". Revista Librújula. Recuperado de: http://www.librujula.com/entrevistas/1992hay-que-comprender-los-enormes-beneficios-que-implica-la-aceptacion-de-la-diferencia-y-del-otro.

Kant, I. (1998) [1795]. Sobre la paz perpetua. Madrid: Tecnos.

Lamberti, L. (2017, 23 de febrero). "La política de los textos". Recuperado de: http://patriciopron.com/la-politica-de-los-textos-una-conversacion-con-luciano-lamberti-para-eterna-cadencia-argentina-ndtl/.

Mandolessi, S. (2011). “¿Es posnacional la literatura argentina contemporánea? Apuntes para un debate”. Mitologías hoy. Recuperado de: https://revistes.uab.cat/mitologias/article/view/v1-mandolessi.

Megías, J. (2017, 21 de noviembre). "Caminando bajo el mar, colgando del amplio cielo: una fábula política”. Cuatro Ojos Magacín. Recuperado de: http://www.cuatroojosmagacin.com/2017/11/21/patricio-pron-laidentidad-no-es-un-punto-de-partida-sino-de-llegada/.

Molloy, S. y Siskind, M. (2006). Poéticas de la distancia: adentro y afuera de la literatura argentina. Buenos Aires: Norma. 
Montes, G. (1990). El corral de la infancia. Buenos Aires: Libros del Quirquincho.

Murcia, V. (2018, 22 de enero). "Patricio Pron: 'Lo más importante de Argentina, a excepción de los afectos, lo llevo conmigo"”. Recuperado de: http:// www.ibe.tv/es/canal/elportalvoz/5365/Patricio-Pron-\%C2\%ABLom\%C3\%A1s-importante-de-Argentina-a-excepci\% $3 \%$ B3n-de-losafectos-lo-llevo-conmigo\%C2\%BB.htm.

Nancy, J. L. (2003). La creación del mundo o la mundialización. Buenos Aires: Paidós.

. (2014). El arte hoy. Buenos Aires: Prometeo Libros.

Nussbaum, M. (1999). Los límites del patriotismo. Identidad, pertenencia y “ciudadanía mundial”. Barcelona: Paidós.

Omeñaca, S. (2018, 10 de enero). El Cuentahílos [Programa radial]. M21 emisora. Recuperado de: https://www.m21radio.es/podcast/el-cuentahilos/el-cuentahilos-10012018.

Pron, P. (2017a). Caminando bajo el mar, colgando del amplio cielo. Madrid: Siruela.

. (2017b, 25 de noviembre). "La vida en otros mundos". El país.

. (2017c). "Trayéndolo todo de regreso a casa: Saer, Copi, Bolaño y la literatura nacional sin nación”. Cuadernos hispanoamericanos 801, 108-119.

Sainz Borgo, C. (2018, 2 de febrero). "Patricio Pron: 'Muy pocos libros de cuentos se sostienen más allá de las primeras cuarenta páginas”'.Zenda. Autores, libros y compañía. Recuperado de: https://www.zendalibros. com/patricio-pron-libros-cuentos-se-sostienen-mas-alla-las-primerascuarenta-paginas/.

Siskind, M. (2016). Deseos cosmopolitas. Modernidad global y literatura mundial en América Latina. Buenos Aires: Fondo de Cultura Económica.

Tentoni, V. (2015, 21 de abril). "Escritores argentinos en el exterior”. Recuperado de: https://eternacadencia.wordpress.com/2015/04/21/viviry-escribir-afuera/.

Topuzian, M. (2014). "La literatura mundial como provocación de los estudios literarios”. Chuy. Revista de estudios literarios latinoamericanos, $\mathrm{n}^{\circ} 1$, año $1,94-138$. 
. (2017). "Introducción: entre la literatura nacional y posnacional”, en Tras la nación. Conjeturas y controversias sobre las literaturas nacionales y mundiales (pp. 9-65). Buenos Aires: Editorial Universitaria de Buenos Aires.

Žižek, S. (2016). "Los límites del amor al prójimo" en La nueva lucha de clases. Los refugiados y el terror. Barcelona: Anagrama. 